\title{
Patient-Family Agenda Setting for Primary Care Patients with Cognitive Impairment: the SAME Page Trial
}

\author{
Jennifer L. Wolff, Ph. ${ }^{7}$, Debra L. Roter, Dr.PH. ${ }^{2}$, Cynthia M. Boyd, MD, MPH ${ }^{3}$, David L. Roth, PhD ${ }^{3}$, \\ Diane M. Echavarria, MAS', Jennifer Aufill, BA ${ }^{7}$, Judith B. Vick, MPH', and Laura N. Gitlin, Ph. $D^{5}$
}

\begin{abstract}
'Roger C. Lipitz Center for Integrated Health Care, Department of Health Policy and Management, Johns Hopkins Bloomberg School of Public Health, Baltimore, MD, USA; ${ }^{2}$ Department of Health, Behavior, and Society, Johns Hopkins Bloomberg School of Public Health, Baltimore, MD, USA; ${ }^{3}$ Division of Geriatric Medicine and Gerontology, Department of Medicine, Johns Hopkins University School of Medicine, Baltimore, MD, USA; ${ }^{4}$ Edward D. Miller Research Building, Johns Hopkins University School of Medicine, Baltimore, MD, USA; ${ }^{5}$ College of Nursing and Health Professions, Drexel University, Philadelphia, PA, USA.
\end{abstract}

BACKGROUND: Establishing priorities for discussion during time-limited primary care visits is challenging in the care of patients with cognitive impairment. These patients commonly attend primary care visits with a family companion.

OBJECTIVE: To examine whether a patient-family agenda setting intervention improves primary care visit communication for patients with cognitive impairment

DESIGN: Two-group pilot randomized controlled study PARTICIPANTS: Patients aged 65 + with cognitive impairment and family companions ( $n=93$ dyads) and clinicians $(n=14)$ from two general and one geriatrics primary care clinic

INTERVENTION: A self-administered paper-pencil checklist to clarify the role of the companion and establish a shared visit agenda

MEASUREMENTS: Patient-centered communication (primary); verbal activity, information disclosure including discussion of memory, and visit duration (secondary), from audio recordings of visit discussion

RESULTS: Dyads were randomized to usual care ( $n=$ $44)$ or intervention $(n=49)$. Intervention participants endorsed an active communication role for companions to help patients understand what the clinician says or means (90\% of dyads), remind patients to ask questions or ask clinicians questions directly (84\% of dyads), or listen and take notes ( $82 \%$ of dyads). Intervention dyads identified 4.4 health issues for the agenda on average: patients more often identified memory (59.2 versus $38.8 \% ; p=0.012)$ and $\operatorname{mood}$ (42.9 versus $24.5 \% ; p=0.013$ ) whereas companions more often identified safety (36.7 versus $18.4 \%$; $p=$ 0.039 ) and personality/behavior change (32.7 versus $16.3 \% ; p=0.011)$. Communication was significantly more patient-centered in intervention than in control visits at general clinics $(p<0.001)$ and in pooled analyses (ratio of 0.86 versus $0.68 ; p=0.046$ ). At general clinics, intervention (versus control) dyads

Electronic supplementary material The online version of this article (https://doi.org/10.1007/s11606-018-4563-y) contains supplementary material, which is available to authorized users.

Received March 6, 2018

Revised May 16, 2018

Accepted June 29, 2018

Published online July 18, 2018 contributed more lifestyle and psychosocial talk $(p<0.001)$ and less biomedical talk $(p<0.001)$ and companions were more verbally active $(p<0.005)$. No intervention effects were found at the geriatrics clinic. No effect on memory discussions or visit duration was observed.

CONCLUSION: Patient-family agenda setting may improve primary care visit communication for patients with cognitive impairment.

TRIAL REGISTRATION: ClinicalTrials.gov: NCT02986958

KEY WORDS: primary care; family caregiving; health communication; cognitive impairment; dementia.

J Gen Intern Med 33(9):1478-86

DOI: $10.1007 / \mathrm{s} 11606-018-4563-y$

(c) Society of General Internal Medicine 2018

\section{INTRODUCTION}

An estimated 10 million Americans are living with cognitive impairment. ${ }^{1,2}$ Most persons with cognitive impairment are treated in primary care. ${ }^{3,4}$ However, structural factors relating to time and reimbursement, clinician factors relating to perceived and actual knowledge of disease, and practice constraints relating to knowledge of and access to appropriate social service referrals inhibit high-quality primary care for this population. ${ }^{5,6}$ Because persons with cognitive impairment have a high burden of co-occurring medical conditions ${ }^{7-}$ ${ }^{9}$, gaps in care quality also affect other conditions, contributing to costly and burdensome treatments, inappropriate medication use, and potentially avoidable hospitalization. ${ }^{10-13}$

Family and unpaid companions are often present during older adults' primary care visits ${ }^{14,15}$ and behave in varied ways that may help or hinder the comprehensiveness and quality of information exchange and medical decision-making. ${ }^{16,17}$ The presence of a family companion poses special challenges within the context of impaired memory and judgment. ${ }^{18}$ Clinicians may be uncertain whether to direct questions to the patient or to an accompanying companion, who may be perceived as a more reliable informant. ${ }^{19}$ Patient and family assessment of treatment priorities commonly 
diverge. ${ }^{20-22}$ Ambiguity about the visit agenda and fear of jeopardizing patient autonomy may inhibit clinicians' ability to engage family within the time constraints of the typical primary care visit. $5,23,24$

Agenda setting is a strategy that seeks to improve the effectiveness of patient-clinician interactions by establishing relational "ground rules," identifying priorities, and negotiating conversational focus. ${ }^{25}$ Although agenda setting is particularly relevant for patients with complex needs, ${ }^{26,}{ }^{27}$ few interventions specifically address the needs of older adults with cognitive impairment or accommodate the reality that nearly 4 in 10 older adults attend medical visits with a family companion. ${ }^{15,16}$ Therefore, building on prior trials of agenda setting, ${ }^{28-30}$ we developed and tested an intervention for older adults who attend medical visits with a family companion. Our goal was to develop a simple, scalable strategy to help patients and families prepare for a primary care visit by setting forth a structured process to clarify expectations regarding the role of the companion and establish a shared visit agenda. A prior proof-of-concept study found this approach to be acceptable and promising, but was limited to a single academic geriatrics clinic and excluded older adults with significant cognitive impairment. ${ }^{31}$ Because we sought to develop an approach that is relevant to a broad range of patients, and because cognitive impairment is under-discussed and under-diagnosed, ${ }^{32,} 33$ the SAME Page trial was designed to examine the effects of patient-family agenda setting on primary care visit communication among older adults with cognitive impairment ranging from mild to severe, regardless of diagnosis.

\section{METHODS}

We conducted a two-group single-blind randomized pilot trial at two general primary care clinics and one hospital-based geriatrics clinic. Eligibility for patients included age 65 or older, English speaking, $1+$ incorrect answer or being unable to respond to a cognitive screening survey,$^{34}$ and attendance in primary care visits with a family member or unpaid companion.

\section{Study Procedures}

Patients of participating clinicians were mailed letters describing the study 1 month in advance of a scheduled visit. Patients who did not "opt out" by mail were contacted by the research team to discuss study procedures and administer a telephone screening interview. Eligible patient-companion dyads who expressed an interest in participating met a member of the research team at the clinic $30 \mathrm{~min}$ before the patient's visit. After each patient and companion provided informed consent, the dyad was randomized using stratified, blocked randomization with alternating block sizes of 4 and 6 for each clinician. Dyads assigned to the intervention were asked to complete the checklist while in the waiting room without instruction from research staff. Dyads assigned to the control group waited for their visit as usual. All visits were audio-recorded. Clinicians, patients (when possible), and companions completed brief written post-visit surveys in the clinic suite. Patients (when possible) and companions were interviewed by telephone 2 weeks after the visit. Our protocol was approved by the institutional review board of the Johns Hopkins Bloomberg School of Public Health (IRB no. 6837).

\section{Intervention}

We developed a one-page paper-pencil checklist to be completed in the waiting room by older adults and their family companion (Fig. 1). The checklist involves two activities. The first activity involves clarifying expectations for the companion's role, from a list of behaviors previously found to be beneficial during medical visits. ${ }^{15,} 16$ The second activity asks patient and companion to each identify concerns about the patient's health and decide together which to discuss with the clinician. Twelve common health issues that are under-recognized in primary care are listed on the checklist, with space so that additional topics may be nominated by the patient or companion. All text is in large (15point) font and readability of the checklist on the Flesch-Kincaid grade level is 8.1 .

\section{Outcomes}

Outcomes were assessed from audio recordings of patients' medical visits, which were coded by trained staff, blinded to

\section{Making the most of your doctor visit}

This conversation guide is for patients who attend doctor visits with a family member or friend. Together, use this guide to prepare for today's visit.

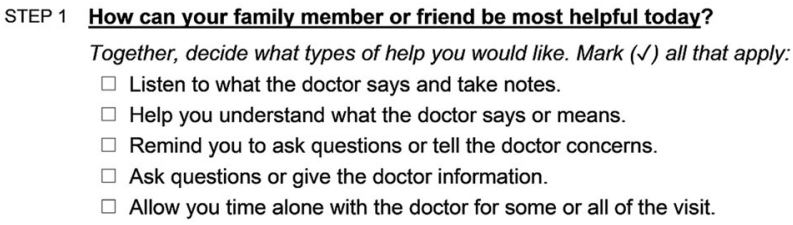

STEP 1 How can your family member or friend be most helpful today?

Together, decide what types of help you would like. Mark $(\checkmark)$ all that apply:

$\square$ Listen to what the doctor says and take notes.

$\square$ Help you understand what the doctor says or means

$\square$ Remind you to ask questions or tell the doctor concerns

$\square$ Ask questions or give the doctor information.

Allow you time alone with the doctor for some or all of the visit.

STEP 2 What do you want to discuss with the doctor today? Together, decide which concerns are most important.

\begin{tabular}{|c|c|c|}
\hline \multirow[b]{2}{*}{ Issues affecting the patient } & \multicolumn{2}{|c|}{$\operatorname{Mark}(\checkmark)$ if a concern to } \\
\hline & PATIENT & FAMILY \\
\hline Hearing or vision & $\square$ & $\square$ \\
\hline Fear of falls, dizziness, or balance & $\square$ & $\square$ \\
\hline Bladder or bowel problems & $\square$ & $\square$ \\
\hline Safety at home or when driving & $\square$ & $\square$ \\
\hline Difficulty bathing, dressing, or walking & $\square$ & $\square$ \\
\hline Financial matters that affect patient health & $\square$ & $\square$ \\
\hline $\begin{array}{l}\text { Planning for serious illness or progression of } \\
\text { current illness }\end{array}$ & $\square$ & $\square$ \\
\hline Changes in personality or behavior & $\square$ & $\square$ \\
\hline Stress, worry, or feeling sad or blue & $\square$ & $\square$ \\
\hline Trouble concentrating or making decisions & $\square$ & $\square$ \\
\hline Memory problems & $\square$ & $\square$ \\
\hline Managing or taking medications & $\square$ & $\square$ \\
\hline & $\square$ & $\square$ \\
\hline & $\square$ & $\square$ \\
\hline & $\square$ & $\square$ \\
\hline
\end{tabular}

Figure 1 SAME Page: Patient-Family Agenda Setting Checklist. 
group assignment using the Roter Interaction Analysis System (RIAS), a validated system for empirically describing medical visit communication. ${ }^{35}$ Our primary outcome was a measure of patient-centered communication, calculated as a ratio of RIAS codes that encompass psychosocial and socioemotional elements of exchange, in the numerator, relative to codes that reflect a biomedical and disease-focused perspective, in the denominator. ${ }^{35,36}$ Prior studies have established predictive and concurrent validity of this measure. ${ }^{24,36-38}$ Higher values indicate more patient-centered communication.

We studied three secondary outcomes. Verbal activity refers to the proportion of visit statements contributed by each speaker in relation to overall visit statements, ${ }^{35}$ as a marker of active engagement in visit discussion. ${ }^{36,39}$ Information disclosure refers to the proportion of visit statements contributed by the patient-companion dyad relating to biomedical talk and lifestyle and psychosocial talk in relation to total visit statements, elements of information exchange that were most affected in our prior proof-of-concept study. ${ }^{31}$ We also examined a dichotomous measure of whether memory discussion was raised in the visit (Online Appendix A). Visit duration, expressed in minutes, reflects resource use and opportunity to engage in comprehensive information exchange. ${ }^{40,41}$

\section{Companion Roles and Visit Priorities}

Companion roles were decided together and visit priorities were identified separately from responses to the agenda setting checklist, as displayed in Figure 1. Measures of patient-companion concordance reflect whether each health issue was selected as a priority by patient only, companion only, neither, or both. The utility, burden, and helpfulness of the checklist were assessed in written post-visit surveys using questions from our formative work. ${ }^{31}$

\section{Additional Measurements}

From patients' electronic health record, we assessed age, gender, and diagnosis of cognitive impairment or dementia at the time of the enrollment visit. The Mini-Mental State Examination (MMSE) ${ }^{42}$ was administered by research staff immediately after the enrollment visit. Patient and companion socio-demographic and health factors were assessed in followup telephone interviews. Clinician characteristics were assessed from surveys administered at the time of informed consent.

\section{Analysis}

Simple statistics (frequency distributions, group means) were used to assess potential differences between eligible patients willing and unwilling to participate, intervention and control participants, and process measures relating to agenda setting completion. The statistical significance of patient-companion discordance on priorities for the visit agenda was assessed with McNemar's test. Intervention effects were examined using regression models in which the main independent variable was treatment assignment and the patient-family dyad was the unit of analysis. We used generalized estimating equations with an exchangeable correlation structure to assess the direction, magnitude, and statistical significance of between-group differences. ${ }^{43}$ Regression models included treatment assignment and patient-level covariates that were postulated as affecting communication outcomes. We conducted pooled and clinic-specific analyses to assess the relevance of primary care context. Statistical tests were two-sided with a significance level of 0.05 . Analyses were performed in SAS statistical software, version 9.4 (SAS, Cary, NC).

\section{Role of the Funding Source}

The study was conducted with grant support from the National Institute on Aging (P30AG048773; R21AG049967). The funding agency did not have a role in the design, conduct, or reporting of the study results.

\section{RESULTS}

\section{Study Sample Characteristics}

All 14 clinicians who met eligibility criteria at the three primary care clinics agreed to participate and provided informed consent. Clinicians were on average 49.3 years (SD, 11.1; range, 29-62), about half were female $(n=7)$, and reported practicing 15 or more years $(n=8$; Table 1$)$. Clinicians were trained in family practice $(n=6)$ or internal

Table 1 Characteristics of Primary Care Clinics and Clinicians

\begin{tabular}{|c|c|c|c|}
\hline $\begin{array}{l}\text { Clinic } \\
\text { characteristics }\end{array}$ & $\begin{array}{l}\text { General } \\
\text { clinic 1 }\end{array}$ & $\begin{array}{l}\text { General } \\
\text { clinic } 2\end{array}$ & $\begin{array}{l}\text { Geriatrics } \\
\text { clinic }\end{array}$ \\
\hline Location of clinic & Suburban & Suburban & Urban \\
\hline Type of facility & Freestanding & Freestanding & $\begin{array}{l}\text { Hospital- } \\
\text { based }\end{array}$ \\
\hline \multicolumn{4}{|l|}{ Clinician characteristics } \\
\hline $\begin{array}{l}\text { Number of enrolled } \\
\text { clinicians }\end{array}$ & 5 & 4 & 5 \\
\hline $\begin{array}{l}\text { Female gender, } n \\
(\%)\end{array}$ & $2(40)$ & $2(50)$ & $3(60)$ \\
\hline \multicolumn{4}{|l|}{ Type of training, $n(\%)$} \\
\hline Family medicine & $3(60)$ & $3(75)$ & $0(0)$ \\
\hline Internal medicine & $1(20)$ & $0(0)$ & $2(40)$ \\
\hline $\begin{array}{l}\text { Nurse practitioner or } \\
\text { physician assistant }\end{array}$ & $1(20)$ & $1(25)$ & $3(60)$ \\
\hline $\begin{array}{l}\text { Specialty training in } \\
\text { geriatrics, } n(\%)\end{array}$ & $1(20)$ & $0(0)$ & $5(100)$ \\
\hline \multicolumn{4}{|l|}{ Years in practice } \\
\hline$<5$ years & $0(0)$ & $1(25)$ & $1(20)$ \\
\hline $5-15$ years & $2(40)$ & $2(50)$ & $0(0)$ \\
\hline$>15$ years & $3(60)$ & $1(25)$ & $4(80)$ \\
\hline \multicolumn{4}{|c|}{ Proportion of panel ages $65+$} \\
\hline$<25 \%$ & $0(0)$ & $2(50)$ & $0(0)$ \\
\hline $25-49 \%$ & $3(60)$ & $2(50)$ & $0(0)$ \\
\hline $50+\%$ & $2(40)$ & $0(0)$ & $5(100)$ \\
\hline \multicolumn{4}{|c|}{ Patient recruitment by clinic } \\
\hline Patients contacted, $n$ & 518 & 167 & 142 \\
\hline $\begin{array}{l}\text { Patients enrolled, } n \\
(\% \text { contacted })\end{array}$ & $43(8.3)$ & $17(10.2)$ & $33(23.2)$ \\
\hline $\begin{array}{l}\text { Mean patients per } \\
\text { clinician (range) }\end{array}$ & $8.6(7-10)$ & $4.3(2-10)$ & $6.6(2-10)$ \\
\hline
\end{tabular}


medicine $(n=3)$, or were nurse practitioners or physician assistants $(n=5)$. Most $(n=5$ of 6$)$ clinicians with geriatrics training practiced at the geriatrics clinic.

Recruitment letters were mailed to 827 patients, of whom $211(25.5 \%)$ returned an "opt-out" card indicating that they were not eligible $(n=95)$ or refusing participation $(n=116)$; $26(3.1 \%)$ could not be reached (Fig. 2). Screening calls were made to 509 (71.3\%) patients, of whom 370 were not eligible, 127 refused participation, and 93 (11.2\%) were eligible and agreed to participate. The 93 dyads were randomized to the control group $(n=44)$ or to the intervention $(n=49)$; all completed follow-up interviews. Patients who participated were older (79.9 versus 76.6 years; $p<0.001)$ than those who did not (data not presented).

About half of the enrolled patients were female (51.6\%), had completed some college (48.4\%), and had a diagnosis of dementia, cognitive impairment, or symptoms of cognitive impairment recorded in their electronic health record (49.5\%; Table 2). Patients' average MMSE score was 21.6 (range, 030 ). Most companions were female $(75.3 \%)$ and were spouses
(39.8\%) or adult children (55.8\%) of patients; few (5.4\%) were friends or other relatives.

\section{Agenda Setting Process}

Intervention patients and companions endorsed an active communication role for companions in helping the patient understand what the clinician says or means $(90 \%)$, reminding the patient to ask questions (84\%), asking questions directly to the clinician $(84 \%)$, or listening and taking notes $(82 \%)$. The majority (84\%) endorsed three or more of these behaviors.

Patients and companions each identified 4.4 health issues (range 0-12) as priorities for the visit agenda on average (Fig. 3). Patient-companion visit priorities were discordant for 4 of the 12 health issues. Patients were more likely than companions to prioritize memory $(59.2$ versus $38.8 \%$; $p=$ 0.012 ) and stress, worry, or feeling sad or blue (42.9 versus $24.5 \% ; p=0.013)$. Companions were more likely than patients to prioritize safety at home or when driving (36.7 versus $18.4 \% ; p=0.039$ ) and changes in personality or behavior $(32.7$ versus $16.3 \%$; $p=0.011)$.

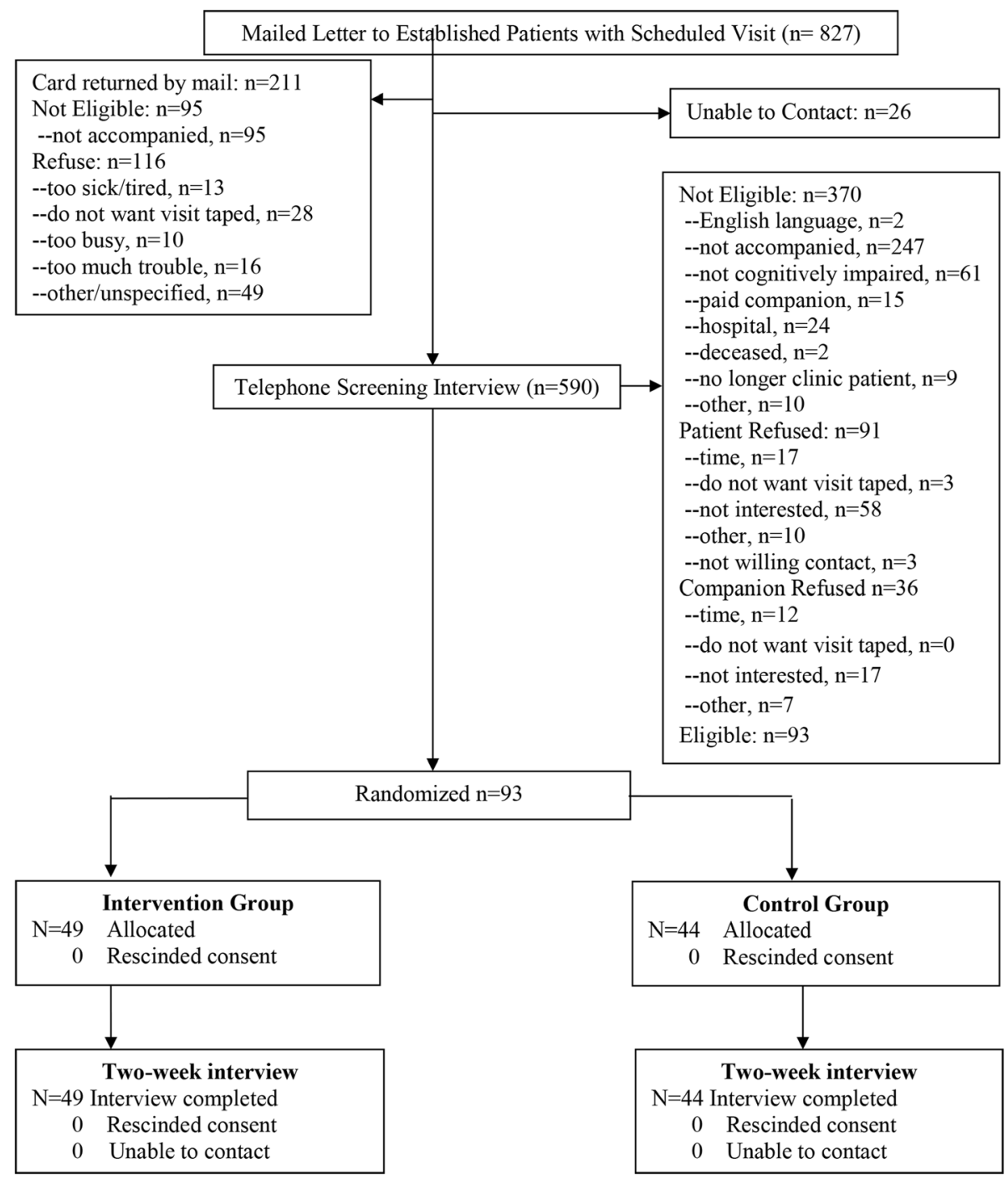

Figure 2 SAME Page Trial: Study Flow Diagram. 
口Patient 口Companion

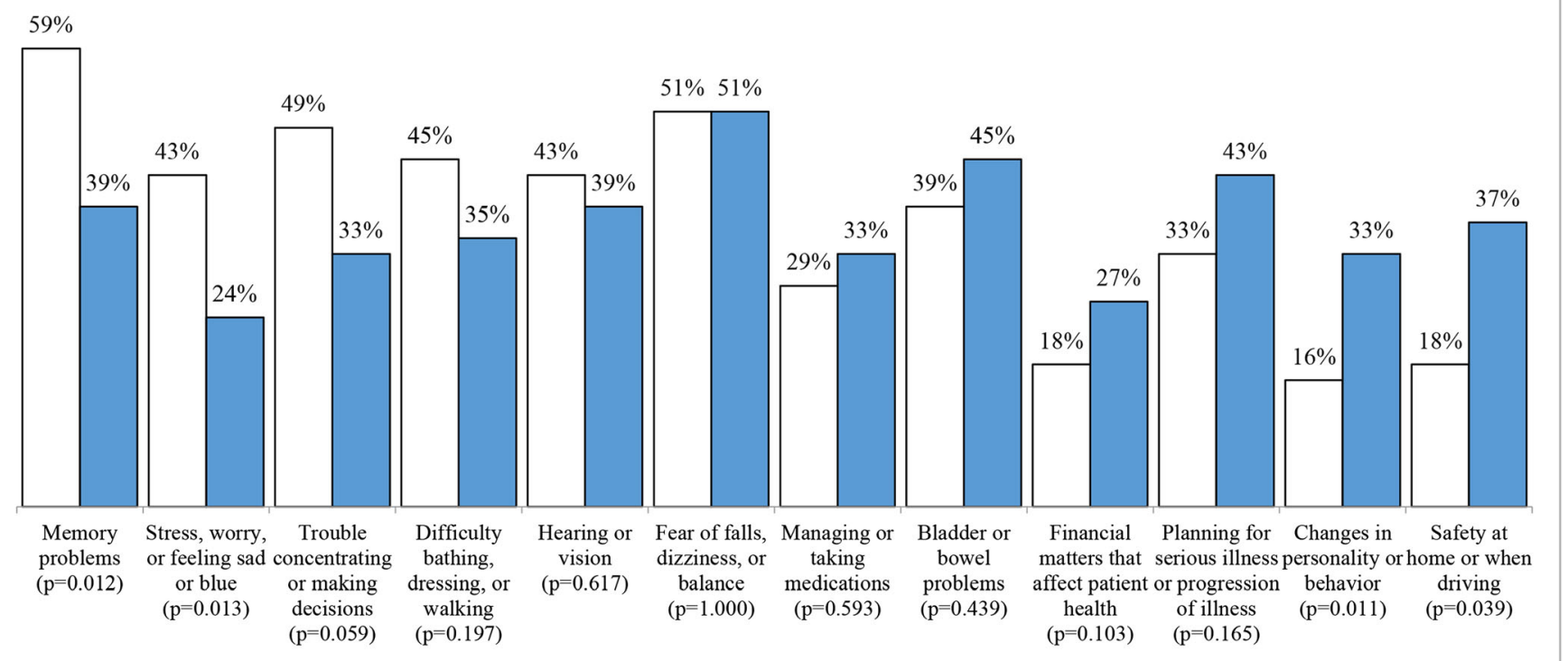

Figure 3 Patient- and Companion-Identified Visit Priorities from SAME Page Agenda Setting Checklist. Intervention Group Only $(n=49)$. $P$ value reflects statistical test of difference in whether each health issue was a priority for the visit (patient only, companion only, both, neither) from McNemar's test.

\section{Intervention Acceptability}

Most companions reported completing the checklist in less than $10 \mathrm{~min}(69.4 \%)$ or $10-15 \mathrm{~min}(26.5 \%)$; few reported taking longer than $15 \mathrm{~min}(4.1 \%)$. Nearly all companions $(95.9 \%)$ stated that the amount of time it took to complete the checklist was "just right." Patients $(n=42)$ and companions $(n=49)$ unanimously agreed or strongly agreed that completing the checklist was easy (Online Appendix B). All patient respondents and $96 \%$ of companions reported that completing the checklist was useful; >90\% reported that completing the checklist was helpful in preparing for their visit, clarifying the role of the companion, remembering concerns, and that completing the checklist made them feel more in control of their care. Most (> 93\%) recommended the checklist to others and reported they would like to continue to use it in the future.

\section{Effects on Visit Communication}

Communication was more patient-centered during visits of intervention than control dyads (ratio of 0.86 versus 0.68 ; $p=0.046$; Table 3). Group differences in patient-centered communication were highly significant at the two general primary care clinics (ratio of 0.89 versus 0.59 at clinic 1 ; $p<0.001$ and 0.68 versus 0.52 at clinic $2 ; p<0.001$ ) but not at the geriatrics clinic.

No group differences in patient or companion verbal activity, information disclosure, or visit duration were observed in pooled analyses. However, intervention (versus control) companions were more verbally active at the two general clinics $(21.3$ versus $16.1 \%$ of visit statements at clinic $1 ; p=0.005$ and 21.5 versus $15.8 \%$ at clinic 2; $p<0.001$ ). A shift toward reduced verbal activity among intervention (versus control) patients was observed at the general clinics and was statistically significant at clinic 2 $(p=0.012)$. At general clinics, intervention (versus control) dyads contributed more statements about lifestyle and psychosocial topics (18.9 versus $10.3 \%$ of visit statements at clinic $1 ; p<0.001$ and 13.9 versus $10.4 \%$ at clinic 2 ; $p<0.001)$ and fewer statements about biomedical topics (31.2 versus $36.1 \%$ of visit statements at clinic $1 ; p<0.001$ and 34.2 versus $42.8 \%$ at clinic $2 ; p<0.001$ ). A shift toward greater memory discussion was observed in intervention (versus control) visits at general clinics which approached statistical significance at clinic 2 (60.0 versus $42.9 \% ; p=0.051)$. No effect on visit duration was found at any of the three clinics.

\section{CONCLUSION}

Results from the SAME Page trial indicate that a brief patient-family agenda setting checklist may improve communication for patients with cognitive impairment who attend primary care visits with a family companion. Intervention participants reported the checklist was easy to complete and helpful. Analyses of visit audio recordings indicate that communication was more patient-centered for 
Table 2 Study Participants by Group Assignment

\begin{tabular}{|c|c|c|c|}
\hline & $\begin{array}{l}\text { Intervention } \\
(n=49)\end{array}$ & $\begin{array}{l}\text { Control } \\
(n=44)\end{array}$ & $\begin{array}{l}P \\
\text { value }\end{array}$ \\
\hline \multicolumn{4}{|l|}{ Patients } \\
\hline Mean age (SD), year & $80.9(8.0)$ & $78.8(7.1)$ & 0.182 \\
\hline Female gender, $n(\%)$ & $24(49.0)$ & $24(54.5)$ & 0.592 \\
\hline $\begin{array}{l}\text { Nonwhite race or } \\
\text { Hispanic ethnicity } n(\%)\end{array}$ & $18(36.7)$ & $21(47.7)$ & 0.284 \\
\hline $\begin{array}{l}\text { Hispanic ethnicity, } n(\%) \\
\text { Lives alone, } n(\%)\end{array}$ & \multicolumn{3}{|c|}{ Hispanic ethnicity, $n(\%)$} \\
\hline $\begin{array}{l}\text { Beyond high school } \\
\text { education, } n(\%)\end{array}$ & $25(51.0)$ & $20(45.5)$ & 0.592 \\
\hline $\begin{array}{l}\text { Receives help with, } n(\%) \\
\text { - Dressing, bathing, } \\
\text { getting around inside }\end{array}$ & $15(30.6)$ & $12(27.3)$ & 0.723 \\
\hline - Managing medications & $26(53.1)$ & $25(56.8)$ & 0.798 \\
\hline - Bills and paperwork & $33(67.3)$ & $26(59.1)$ & 0.409 \\
\hline - Coordination of care & $39(79.6)$ & $29(65.9)$ & 0.137 \\
\hline $\begin{array}{l}\text { Companion is the person } \\
\text { who helps "the most"* }\end{array}$ & $36(85.7)$ & $36(97.3)$ & 0.071 \\
\hline $\begin{array}{l}\text { Diagnosis of cognitive } \\
\text { impairment, } n(\%)^{\dagger}\end{array}$ & $27(55.1)$ & $19(43.2)$ & 0.292 \\
\hline $\begin{array}{l}\text { Mean number of } \\
\text { prescribed medications } \\
\text { (SD) }\end{array}$ & $7.6(4.1)$ & $6.6(5.0)$ & 0.327 \\
\hline $\begin{array}{l}\text { Mean Mini-Mental State } \\
\text { Examination score (SD) }\end{array}$ & $20.8(7.8)$ & $22.5(5.5)$ & 0.243 \\
\hline $\begin{array}{l}\text { Fair or poor self-rated } \\
\text { health, } n(\%)^{\ddagger}\end{array}$ & $31(63.3)$ & $23(52.3)$ & 0.284 \\
\hline \multicolumn{4}{|l|}{ Companions } \\
\hline Female gender, $n(\%)$ & $34(69.4)$ & $36(81.8)$ & 0.165 \\
\hline \multicolumn{4}{|l|}{ Relationship to patient, $n(\%)$} \\
\hline $\begin{array}{l}\text { - Spouse/partner } \\
\text { - Adult child }\end{array}$ & $\begin{array}{l}22(44.9) \\
27(55.1)\end{array}$ & $\begin{array}{l}15(34.1) \\
24(54.5)\end{array}$ & 0.044 \\
\hline $\begin{array}{l}\text { - Other (friend, other } \\
\text { relative) }\end{array}$ & $0(0.0)$ & $5(11.4)$ & \\
\hline $\begin{array}{l}\text { Fair or poor self-rated } \\
\text { health, } n(\%)\end{array}$ & $10(20.4)$ & $9(20.5)$ & 0.996 \\
\hline $\begin{array}{l}\text { Beyond high school } \\
\text { education, } n(\%)\end{array}$ & $37(75.5)$ & $30(68.2)$ & 0.432 \\
\hline
\end{tabular}

Percentages may not sum due to rounding

*Estimates for the 42 intervention and 37 control group patients who were receiving help

tDiagnoses from chart review of electronic health record at the time of enrollment

$\ddagger$ Patient self-rated health as reported by companion

dyads randomized to agenda setting than dyads randomized to usual care. At the two general primary care clinics, intervention companions were more verbally active in visit discussion and intervention dyads contributed more lifestyle and psychosocial talk and less biomedical talk than those who received usual care. The lack of intervention effects at the geriatrics clinic may be due to practice-level contextual factors: visits on average exceeded $35 \mathrm{~min}$ in duration, companions were verbally active, and communication was highly patient-centered, irrespective of intervention assignment. Taken together, findings indicate that the intervention led to more notable effects at the general primary care clinics where communication shifted to more closely approximate than that observed in geriatrics clinic visits. The absence of an effect on visit duration indicates that patient-family agenda setting did not impose additional time demands.

Our intervention establishes a structured process to clarify the expected role of the companion, prioritize concerns about the patient's health, and develop shared focus for the visit agenda. It is notable that intervention patients and companions selected an active role for the companion in visit discussion yet reported distinct individual priorities for the visit agenda. Although some issues were similarly prioritized, memory and mood were more often identified by patients whereas safety and behavior/personality change were more often identified by companions. These topics are often under-recognized and unaddressed in primary care, yet are essential to highquality dementia care. ${ }^{5,44,45}$ Although we did not observe a pooled intervention effect on discussion of memory, intervention dyads were more likely than control dyads to discuss memory at the two general clinics and this effect approached statistical significance at general clinic 2. That intervention (versus control) dyads contributed more information about lifestyle and psychosocial topics suggests the intervention empowered patients and companions to raise the nonmedical priorities which are less likely to be identified ${ }^{46,47}$ and challenging to address within the context of the typical 15min primary care visit. ${ }^{48,49}$

Despite the pivotal role of family in the health and health care of older adults with cognitive impairment, ${ }^{15,}{ }^{16}$ evidencebased strategies that recognize and integrate patient and family perspectives are lacking. Agenda setting clarifies conversational focus, aligns expectations, and establishes relational ground rules to enhance the patient-centeredness and efficiency of time-limited clinical encounters. ${ }^{25}$ These objectives are particularly important, yet challenging in the context of cognitive impairment. By translating the traditional orientation of agenda setting from patient-clinician to patient-companion, our intervention addresses the reality that many older persons navigate health system demands in partnership with family or close friends. ${ }^{50,51}$ By striving to respect patient preferences and clarify expectations regarding the companion role, our intervention is aligned with principles of person- and familycentered care in acknowledging the valuable perspective and contributions that a family may assume in ensuring an effective therapeutic alliance with clinicians. ${ }^{50,52}$

The consistency of results from the SAME Page trial and our initial proof-of-concept study ${ }^{31}$ provide preliminary support of intervention replicability. We believe that our intervention affects visit communication through pathways that involve strengthening patient-companion relational rapport, developing shared focus for visit discussion, and preparing the companion to meet patient's expectations and preferences for communication support. Although our study contributes granular information regarding patient and companion visit priorities and objective measures of visit communication, we are unable to quantitatively assess the causal mechanism by which agenda setting affected communication. We interpret differences in patient and companion visit priorities as indicating that the process of formulating a shared agenda stimulated discussion of individual perspectives and greater confidence and ability to advocate for productive information exchange with the clinician.

We note several limitations. Our study was not designed nor powered to detect between-group differences by clinic or 
Table 3 Communication Outcomes in Intervention and Control Groups, Overall and by Primary Care Clinic

\begin{tabular}{|c|c|c|c|c|c|c|}
\hline \multirow[t]{2}{*}{ All primary care clinics } & \multirow[t]{2}{*}{$\begin{array}{l}\text { Intervention }(n= \\
49)\end{array}$} & \multirow[t]{2}{*}{$\begin{array}{l}\text { Control }(n= \\
44)\end{array}$} & \multicolumn{2}{|c|}{$\begin{array}{l}\text { Unadjusted analysis } \\
\text { group difference }\end{array}$} & \multicolumn{2}{|c|}{$\begin{array}{l}\text { Adjusted analysis group } \\
\text { difference }\end{array}$} \\
\hline & & & $\begin{array}{l}\text { Estimate } \\
\text { (SE) }\end{array}$ & $\begin{array}{l}P \\
\text { value }\end{array}$ & $\begin{array}{l}\text { Estimate } \\
\text { (SE) }\end{array}$ & $\begin{array}{l}P \\
\text { value }\end{array}$ \\
\hline $\begin{array}{l}\text { Mean ratio of patient-centered communication } \\
\text { (SD)* }\end{array}$ & $0.86(0.42)$ & $0.68(0.45)$ & $0.18(0.06)$ & 0.002 & $0.16(0.08)$ & 0.046 \\
\hline \multicolumn{7}{|l|}{ Mean verbal activity $(\mathrm{SD})^{\dagger}$} \\
\hline Patient & $22.6(0.14)$ & $27.1(0.14)$ & $-0.05(0.03)$ & 0.068 & $-0.03(0.02)$ & 0.230 \\
\hline \multirow{2}{*}{\multicolumn{7}{|c|}{ Patient and companion information disclosure $(\%)^{\ddagger}$}} \\
\hline & & & & & & \\
\hline Biomedical talk & 32.9 & 36.1 & $-0.04(0.02)$ & 0.086 & $-0.03(0.02)$ & 0.121 \\
\hline Lifestyle and psychosocial talk & 18.1 & 12.8 & $0.06(0.02)$ & $<0.001$ & $0.05(0.02)$ & 0.004 \\
\hline Discussion of memory (\%) & 34.7 & 36.4 & $-0.02(0.09)$ & 0.829 & $-0.02(0.07)$ & 0.800 \\
\hline $\begin{array}{l}\text { Mean visit duration, minutes (SD) } \\
\text { General Clinic } 1\end{array}$ & $\begin{array}{l}25.5(12.5) \\
(n=21)\end{array}$ & $\begin{array}{l}24.8(15.2) \\
(n=22)\end{array}$ & $0.81(2.02)$ & 0.688 & $1.25(2.16)$ & 0.563 \\
\hline $\begin{array}{l}\text { Mean ratio of patient-centered communication } \\
\text { (SD)* }\end{array}$ & $0.89(0.34)$ & $0.59(0.23)$ & $0.30(0.05)$ & $<0.001$ & $0.33(0.05)$ & $<0.001$ \\
\hline \multicolumn{7}{|l|}{ Mean verbal activity ${ }^{\dagger}$} \\
\hline Patient & $24.4(0.16)$ & $30.0(0.14)$ & $-0.06(0.04)$ & 0.126 & $-0.04(0.03)$ & 0.080 \\
\hline \multirow{2}{*}{\multicolumn{7}{|c|}{ Patient and companion information disclosure $(\%)^{\ddagger}$}} \\
\hline & & & & & & \\
\hline Biomedical talk & 31.2 & 36.1 & $-0.05(0.01)$ & $<0.001$ & $-0.06(0.01)$ & $<0.001$ \\
\hline Lifestyle and psychosocial talk & 18.9 & 10.3 & $0.09(0.02)$ & $<0.001$ & $0.09(0.02)$ & $<0.001$ \\
\hline Discussion of memory (\%) & 22.7 & 19.0 & $0.05(0.08)$ & 0.518 & $0.05(0.06)$ & 0.351 \\
\hline $\begin{array}{l}\text { Mean visit duration, minutes (SD) } \\
\text { General Clinic } 2\end{array}$ & $\begin{array}{l}18.9(10.34) \\
(n=10)\end{array}$ & $\begin{array}{l}16.1(9.34) \\
(n=7)\end{array}$ & $2.54(2.81)$ & 0.367 & $3.64(2.89)$ & 0.208 \\
\hline $\begin{array}{l}\text { Mean ratio of patient-centered communication } \\
\text { (SD)* }\end{array}$ & $0.68(0.44)$ & $0.52(0.40)$ & $0.18(0.08)$ & 0.029 & $0.18(0.03)$ & $<0.001$ \\
\hline \multicolumn{7}{|l|}{ Mean verbal activity $(\mathrm{SD})^{\dagger}$} \\
\hline Patient & $26.5(0.08)$ & $30.8(0.12)$ & $-0.04(0.07)$ & 0.600 & $-0.08(0.03)$ & 0.012 \\
\hline \multirow{2}{*}{\multicolumn{7}{|c|}{ Patient and companion information disclosure $(\%)^{\ddagger}$}} \\
\hline & & & & & & \\
\hline Biomedical talk & 34.2 & 42.8 & $-0.14(0.06)$ & 0.035 & $-0.17(0.02)$ & $<0.001$ \\
\hline Lifestyle and psychosocial talk & 13.9 & 10.4 & $0.04(0.03)$ & 0.204 & $0.05(0.01)$ & $<0.001$ \\
\hline Discussion of memory $(\%)$ & 60.0 & 42.9 & $0.18(0.16)$ & 0.258 & $0.21(0.11)$ & 0.051 \\
\hline Mean visit duration, minutes (SD) & $24.2(9.81)$ & $23.6(8.31)$ & $0.94(2.80)$ & 0.736 & $1.04(1.53)$ & 0.494 \\
\hline Geriatrics clinic & $(n=17)$ & $(n=16)$ & & & & \\
\hline $\begin{array}{l}\text { Mean ratio of patient-centered communication } \\
\text { (SD)* }\end{array}$ & $0.93(0.49)$ & $0.88(0.61)$ & $0.05(0.09)$ & 0.576 & $-0.01(0.13)$ & 0.987 \\
\hline \multicolumn{7}{|l|}{ Mean verbal activity $(\mathrm{SD})^{\dagger}$} \\
\hline Patient & $17.9(0.13)$ & $21.6(0.14)$ & $-0.04(0.04)$ & 0.336 & $0.01(0.03)$ & 0.894 \\
\hline & $25.4(0.13)$ & $22.1(0.12)$ & $0.05(0.04)$ & 0.225 & $0.01(0.04)$ & 0.803 \\
\hline \multicolumn{7}{|c|}{ Patient and companion information disclosure $(\%)^{*}$} \\
\hline Biomedical information talk & 34.4 & 33.3 & $0.01(0.02)$ & 0.540 & $0.04(0.02)$ & 0.072 \\
\hline Lifestyle and psychosocial talk & 19.5 & 17.1 & $0.02(0.02)$ & 0.111 & $0.01(0.02)$ & 0.589 \\
\hline Discussion of memory $(\%)$ & 35.3 & 56.3 & $-0.20(0.18)$ & 0.273 & $-0.15(0.15)$ & 0.300 \\
\hline Mean visit duration, minutes (SD) & $34.8(11.00)$ & $36.7(16.12)$ & $-1.55(3.71)$ & 0.675 & $-1.30(3.56)$ & 0.715 \\
\hline
\end{tabular}

*Higher values indicate more patient-centered communication. Patient-centered communication is a ratio of psychosocial and socio-emotional statements relative to biomedical talk and orientation. The numerator includes physician psychosocial questions, lifestyle, and psychosocial information giving and counseling; facilitation and activation; and positive and emotional talk as well as patient and companion biomedical and psychosocial questions, psychosocial and lifestyle disclosure, and emotional talk. The denominator includes physician biomedical questions, biomedical information giving and counseling, and procedural talk as well as patient and companion biomedical disclosure

Ferbal activity reflects the proportion of statements contributed by the patient and the companion in relation to overall visit statements (including statements by the physician)

$\mp$ Refers to the proportion of statements contributed by the patient and companion within each Roter Interaction Analysis System summary category relative to total patient and companion visit statements (see Roter and Larson 2002)

${ }^{\S}$ Accounts for clustering by primary care clinician

${ }^{\natural}$ Accounts for clustering by primary care clinician and adjusts for covariates of patient age, gender, and cognitive function based on Mini-Mental State Examination score

patient subgroup, such as dementia severity. Data were restricted to a single medical encounter. We examined a binary measure of whether any memory discussion occurred as opposed to the duration or comprehensiveness of discussion. Although the study design supports a high level of internal validity, a large number of participants were targeted and those who were eligible and agreed to participate may differ from those who did not. As the study was conducted in three primary care clinics in a single metropolitan area, additional research is necessary to determine whether findings generalize to mainstream primary care. Future studies should evaluate the replicability and implementation potential of the SAME Page checklist using alternative delivery modalities and in concert with broader care delivery redesign and practice transformation initiatives. ${ }^{53,54}$

Person- and family-centered care has been described as the pinnacle of care quality, and a central element of a highperforming health system. ${ }^{55,56}$ This study finds patient- 
family agenda setting holds promise as a simple and scalable strategy to improve communication for the subgroup of primary care patients living with cognitive impairment who are accompanied to primary care visits. Our approach resonates with contemporary initiatives to improve the quality of dementia care, ${ }^{54,57,58}$ identify and address non-medical factors in health care delivery, ${ }^{59}$ and engage family caregivers who often play a critical role in bridging health system demands for persons with greater vulnerability and dementia. ${ }^{45,}{ }^{60}$ The strategy that we have developed involves limited impacts to primary care practice workflows and could be readily disseminated.

Contributors: The authors thank the following people without whom the study would not have been possible: Dana Frank, MD, and George Hennawi, MD, from the Health, Economics, and Aging Research Institute and Kelly M. Smith, PhD, of the MedStar Institute for Quality and Safety; Wendy Greenberg and Todd Nesson, and clinicians and staff at Johns Hopkins Community Physicians; John Mulcahy and Kaylin Ford for preparation of the study randomization algorithm; and the patients, family members, and primary care clinicians who participated in the study.

Prior presentations: Portions of this work have been presented at meetings of the American Geriatrics Society (May 2016), the Gerontological Society of America (July 2017), and Academy Health (June 2018).

Corresponding Author: Jennifer L. Wolff, Ph.D; Roger C. Lipitz Center for Integrated Health Care, Department of Health Policy and ManagementJohns Hopkins Bloomberg School of Public Health, Baltimore, MD, USA (e-mail: jwolff2@jhu.edu).

Author's Contributions (1) Substantial contributions to conception and design (JLW, DLR, CMB, DLR, JV, LNG), or acquisition of data (JLW, DE, JA), or analysis and interpretation of data (JLW, DLR, CMB, $D L R, J V, L N G)$; (2) drafting the article (JLW) or revising it critically for important intellectual content ( $J W, D L R, C M B, D L R, D E, J A, J V, L N G$ ); and (3) final approval of the version to be published (JLW, DLR, CMB, $D L R, D E, J A, J V, L N G)$. Dr. Wolff had full access to all of the data in the study and takes responsibility for the integrity of the data and accuracy of the data analysis.

Funders This study was supported by the National Institute of Aging grants R21AG049967 (JLW PI) and P30AG048773 (DLR PI). The sponsor of this research was not involved in its study concept or design, recruitment of subjects or acquisition of data, data analysis or interpretation, or in the preparation of this manuscript.

\section{Compliance with Ethical Standards:}

Our protocol was approved by the institutional review board of the Johns Hopkins Bloomberg School of Public Health (IRB no. 6837).

Conflict of Interest: The authors declare that they do not have a conflict of interest.

\section{REFERENCES:}

1. Plassman BL, Langa KM, Fisher GG, Heeringa SG, Weir DR, Ofstedal MB, et al. Prevalence of cognitive impairment without dementia in the United States. Ann Intern Med. 2008;148(6):427-34.

2. Plassman BL, Langa KM, Fisher GG, Heeringa SG, Weir DR, Ofstedal MB, et al. Prevalence of dementia in the United States: the aging, demographics, and memory study. Neuroepidemiology. 2007;29(12): $125-32$

3. Geldmacher DS, Kerwin DR. Practical Diagnosis and Management of Dementia Due to Alzheimer's Disease in the Primary Care Setting: An Evidence-Based Approach. Prim Care Companion CNS Disord. 2013;15(4).

4. Boustani M, Sachs G, Callahan CM. Can primary care meet the biopsychosocial needs of older adults with dementia? J Gen Intern Med. 2007;22(11):1625-7.

5. Hinton L, Franz CE, Reddy G, Flores Y, Kravitz RL, Barker JC. Practice constraints, behavioral problems, and dementia care: primary care physicians' perspectives. J Gen Intern Med. 2007;22(11):1487-92.

6. Harris DP, Chodosh J, Vassar SD, Vickrey BG, Shapiro MF. Primary care providers' views of challenges and rewards of dementia care relative to other conditions. J Am Geriatr Soc. 2009;57(12):2209-16.

7. Schubert CC, Boustani M, Callahan CM, Perkins AJ, Carney CP, Fox C, et al. Comorbidity profile of dementia patients in primary care: are they sicker? J Am Geriatr Soc. 2006;54(1): 104-9.

8. Hurd MD, Martorell P, Delavande A, Mullen KJ, Langa KM. Monetary costs of dementia in the United States. N Engl J Med. 2013;368(14): 1326-34.

9. Kuo TC, Zhao Y, Weir S, Kramer MS, Ash AS. Implications of comorbidity on costs for patients with Alzheimer disease. Med Care. 2008;46(8):839-46.

10. Thorpe JM, Thorpe CT, Kennelty KA, Gellad WF, Schulz R. The impact of family caregivers on potentially inappropriate medication use in noninstitutionalized older adults with dementia. Am J Geriatr Pharmacother. 2012;10(4):230-41.

11. Roe CM, Anderson MJ, Spivack B. Use of anticholinergic medications by older adults with dementia. J Am Geriatr Soc. 2002;50(5):836-42.

12. Bynum J, Rabins P, Weller W, Niefeld M, Anderson G, Wu A. The relationship between a dementia diagnosis, chronic illness, medicare expenditures, and hospital use. J Am Geriatr Soc. 2004;52(2):187-94.

13. Lin PJ, Fillit HM, Cohen JT, Neumann PJ. Potentially avoidable hospitalizations among Medicare beneficiaries with Alzheimer's disease and related disorders. Alzheimers Dement. 2013;9(1):30-8.

14. Wolff JL, Spillman BC, Freedman VA, Kasper JD. A national profile of family and unpaid caregivers who assist older adults with health care activities. JAMA Intern Med. 2016;176(3):372-9.

15. Wolff $\mathbf{J L}$, Roter DL. Hidden in plain sight: Medical visit companions as a quality of care resource for vulnerable older adults. Arch Intern Med. 2008;168(13):1409-15.

16. Wolff $\mathbf{J L}$, Roter DL. Family presence in routine medical visits: A metaanalytical review. Soc Sci Med. 2011;72(6):823-31.

17. Laidsaar-Powell RC, Butow PN, Bu S, Charles C, Gafni A, Lam ww, et al. Physician-patient-companion communication and decision-making: A systematic review of triadic medical consultations. Patient Educ Couns. 2013;91(1):3-13.

18. Vick J, Amjad H, Smith KC, Boyd CM, Gitlin LN, Roth DL, et al. "Let him speak:" A descriptive qualitative study of the roles and behaviors of family companions in primary care visits among older adults with cognitive impairment. Int J Geriatr Psychiatry. 2018;33(1):e103-e12.

19. Bradford A, Upchurch C, Bass D, Judge K, Snow AL, Wilson N, et al. Knowledge of documented dementia diagnosis and treatment in veterans and their caregivers. Am J Alzheimers Dis Other Demen. 2011;26(2):127-33.

20. Silveira MJ, Given CW, Given B, Rosland AM, Piette JD. Patientcaregiver concordance in symptom assessment and improvement in outcomes for patients undergoing cancer chemotherapy. Chronic Illn. 2010;6(1):46-56.

21. Glazier S, Schuman J, Keltz E, Vally A, Glazier R. Taking the next steps in goal ascertainment: a prospective study of patient, team, and family perspectives using a comprehensive standardized menu in a geriatric assessment and treatment unit. J Am Geriatr Soc. 2004;52(2):284-9.

22. Reamy AM, Kim K, Zarit SH, Whitlatch CJ. Values and preferences of individuals with dementia: perceptions of family caregivers over time. Gerontologist. 2013;53(2):293-302.

23. Hirschman KB, Kapo JM, Karlawish JH. Identifying the factors that facilitate or hinder advance planning by persons with dementia. Alzheimer Dis Assoc Disord. 2008;22(3):293-8.

24. Wolff $\mathbf{J L}$, Roter DL. Older adults' mental health function and patientcentered care: does the presence of a family companion help or hinder communication? J Gen Intern Med. 2012;27(6):661-8.

25. Gobat N, Kinnersley P, Gregory JW, Robling $\mathbf{M}$. What is agenda setting in the clinical encounter? Consensus from literature review and expert consultation. Patient Educ Couns. 2015;98(7):822-9. 
26. Kowalski CP, McQuillan DB, Chawla N, Lyles C, Altschuler A, Uratsu CS, et al. 'The Hand on the Doorknob': Visit Agenda Setting by Complex Patients and Their Primary Care Physicians. J Am Board Fam Med. 2018;31(1):29-37.

27. Grant RW, Adams AS, Bayliss EA, Heisler M. Establishing visit priorities for complex patients: A summary of the literature and conceptual model to guide innovative interventions. Healthcare (Amst). 2013;1(3-4):117-22.

28. Harrington $\mathbf{J}$, Noble $\mathbf{L}$, Newman $\mathbf{S}$. Improving patients' communication with doctors: a systematic review of intervention studies. Patient Educ Couns. 2004;52(1):7-16.

29. Kinnersley P, Edwards A, Hood K, Ryan R, Prout H, Cadbury N, et al. Interventions before consultations to help patients address their information needs by encouraging question asking: systematic review. BMJ. 2008;337:a485.

30. Haywood K, Marshall S, Fitzpatrick R. Patient participation in the consultation process: a structured review of intervention strategies. Patient Educ Couns. 2006;63(1-2):12-23.

31. Wolff JL, Roter DL, Barron J, Boyd CM, Leff B, Finucane T, et al. A tool to strengthen the older patient-companion partnership in primary care: Results from a pilot study. J Am Geriatr Soc. 2014;62(2):312-9.

32. Callahan CM, Hendrie HC, Tierney WM. Documentation and evaluation of cognitive impairment in elderly primary care patients. Ann Intern Med. 1995; 122(6):422-9.

33. Amjad H, Roth DL, Sheehan OC, Lyketsos CG, Wolff JL, Samus QM. Underdiagnosis of Dementia: an Observational Study of Patterns in Diagnosis and Awareness in US Older Adults. J Gen Intern Med. 2018.

34. Callahan CM, Unverzagt FW, Hui SL, Perkins AJ, Hendrie HC. Six-item screener to identify cognitive impairment among potential subjects for clinical research. Med Care. 2002;40(9):771-81.

35. Roter D, Larson S. The Roter interaction analysis system (RIAS): utility and flexibility for analysis of medical interactions. Patient Educ Couns. 2002;46(4):243-51.

36. Mead N, Bower P. Measuring patient-centredness: a comparison of three observation-based instruments. Patient Educ Couns. 2000;39(1):71-80.

37. Cooper L, Roter D, Johnson R, Ford D, Steinwachs D, Powe N. Patientcentered communication, ratings of care, and concordance of patient and physician race. Ann Intern Med. 2003;139(11):907-15.

38. Cooper LA, Roter DL, Carson KA, Bone LR, Larson SM, Miller ER, 3rd, et al. A randomized trial to improve patient-centered care and hypertension control in underserved primary care patients. J Gen Intern Med. 2011;26(11):1297-304.

39. Patient-centered care for older adults with multiple chronic conditions: a stepwise approach from the american geriatrics society: american geriatrics society expert panel on the care of older adults with multimorbidity. J Am Geriatr Soc. 2012;60(10):1957-68.

40. Chen L, Farwell W, Jha A. Primary care visit duration and quality: does good care take longer? Arch Intern Med. 2009;169(20):1866-72.

41. Levinson W, Pizzo PA. Patient-physician communication: it's about time. JAMA. 2011; 305 (17):1802-3.

42. Folstein MF, Folstein SE, McHugh PR. Mini-Mental State: A practical method for grading the cognitive state of patients for the clinician. J Psychiat Res. 1975; 12:189-98.

43. Zeger $\mathbf{S}$, Liang $\mathbf{K}$. Longitudinal data analysis for discrete and continuous outcomes. Biometrics. 1986; 42(1): 121-30.
44. Chodosh J, Petitti DB, Elliott M, Hays RD, Crooks VC, Reuben DB, et al. Physician recognition of cognitive impairment: evaluating the need for improvement. J Am Geriatr Soc. 2004;52(7):1051-9.

45. Callahan CM, Sachs GA, Lamantia MA, Unroe KT, Arling G, Boustani MA. Redesigning systems of care for older adults with Alzheimer's disease. Health Aff (Millwood). 2014; 33(4):626-32.

46. Freidin RB, Goldman L, Cecil RR. Patient-physician concordance in problem identification in the primary care setting. Ann Intern Med. 1980;93(3):490-3.

47. Zulman DM, Kerr EA, Hofer TP, Heisler M, Zikmund-Fisher BJ. Patient-provider concordance in the prioritization of health conditions among hypertensive diabetes patients. J Gen Intern Med. 2010;25(5):408-14.

48. Fiscella K, Epstein R. So much to do, so little time: care for the socially disadvantaged and the 15-minute visit. Arch Intern Med. 2008; 168(17):1843-52.

49. Ostbye T, Yarnall KS, Krause KM, Pollak KI, Gradison M, Michener JL. Is there time for management of patients with chronic diseases in primary care? Ann Fam Med. 2005;3(3):209-14.

50. Wolff JL, Boyd CM. A look at person- and family-centered care among older adults: Results from a national survey. J Gen Intern Med. 2015;30(10): 1497-504.

51. Wolff JL, Spillman BC. Older adults receiving assistance with physician visits and prescribed medications and their family caregivers: Prevalence, characteristics, and hours of care. J Gerontol B Psychol Sci Soc Sci. 2014;69(Suppl 1):S65-72.

52. McDaniel S, Campell T, Hepworth J, Lorenz A. Family-Oriented Primary Care. 2nd ed. New York, NY: Springer; 2005.

53. Smith KM, Baker K, Wesley D. Guide to Improving Patient Safety in Primary Care Settings by Engaging Patients and Families: Environmental Scan Report. In: Quality AfHRa, ed. Rockville, MD; 2017.

54. Borson S, Chodosh J, Cordell C, Kallmyer B, Boustani M, Chodos A, et al. Innovation in care for individuals with cognitive impairment: Can reimbursement policy spread best practices? Alzheimers Dement. 2017;13(10): 1168-73.

55. NQF. Final Report: Addressing Performance Measure Gaps in PersonCentered Care and Outcomes. 2014.

56. DHHS. Working for quality: 2013 Annual progress report to Congress: National Strategy for Quality Improvement in Health Care. Washington, DC; 2013.

57. ASPE. National Plan to Address Alzheimer's Disease. Washingnton DC: United States Department of Health and Human Services; 2016.

58. NQF. Priority setting for health care performance measurement: Addressing performance measure gaps for dementia, including Alzheimer's Disease. Washington, DC: National Quality Forum; 2014.

59. NASEM. Accounting for social risk factors in Medicare payment. In: Kwan LY, Stratton K, Steinwachs D, eds. Washington DC: The National Academies Press; 2017.

60. NASEM. Families Caring for an Aging America. Washington, DC: National Academies of Sciences, Engineering, and Medicine; 2016. 